Note

\title{
Development of a Novel Scanning Thermal Microscopy (SThM) Method to Measure the Thermal Conductivity of Biological Cells
}

\author{
KOUICHI NAKANISHI ${ }^{1}$, AKINORI KOGURE ${ }^{2}$, RITSUKO KUWANA ${ }^{3}$, \\ HIROMU TAKAMATSU ${ }^{3}$, AND KIYOSHI ITO ${ }^{3}$ \\ 'Nano-Microbio Research Laboratory, 2-45-10 Komazawa Setagaya-ku Tokyo 154-0012, Japan \\ ${ }^{2}$ Shimadzu Techno-Research, 380-1 Horiyamashita, Hadano, Kanagawa 259-1304, Japan \\ ${ }^{3}$ Faculty of Pharmaceutical Sciences, Setsunan University, 45-1 Nagaotoge-cho, Hirakata, \\ Osaka 573-0101, Japan
}

Received 28 September, 2016/Accepted 28 February, 2017

\begin{abstract}
Differences in the physical properties of individual cells cannot be evaluated with conventional experimental methods that are used to study groups of cells obtained from pure cultures. To examine the differences in the thermal tolerance of individual cells that are genetically identical, a method is needed to measure the thermal energy required to kill single cells. We developed a scanning thermal microscopy (SThM) system and measured the thermal conductivity of various bacterial cells, for example, spore formeing Bacillus genus and non spore-forming bacteria such as Escherichia coli. The thermal conductivity of vegetative cells $(0.61$ to $0.75 \mathrm{~W} / \mathrm{m} \cdot \mathrm{K})$ was found to be higher than that of spores $(0.29$ to $0.45 \mathrm{~W} / \mathrm{m} \cdot \mathrm{K})$. Furthermore the newly developed method enables us to estimate the thermal energy needed to kill individual cells or spores. We believe that this method can estimate the thermal energy required to achieve the cell for sterilization by heating.
\end{abstract}

Key words : Thermal conductivity / Scanning probe microscope / Heat resistance / Coefficient of linear expansion / Transition temperature.

The conventional heat-resistant test methods which use a heating temperature and the $\mathrm{D}$ value, for example, thermal death time (TDT) tubes for the time when heating time reaches a one-tenth survival bacteria, were a method to measure the cell biomass of the stock which became single-mindedness and was not able to evaluate the heat properties of matter of individual cell. In this study, to determine what causes differences in heat resistance between individual cells that are genetically identical, and now to clarify what kind of relation heat resistance expressed with an individual heat properties of individual cell and spore, between a transition temperature, the coefficient of linear expansion and a thermal conductivity to a $\mathrm{D}$ level, we developed a method to measure the thermal energy required to kill individual cells. We previously reported the development of a nano thermal analysis (nanoTA) (Anasys Instrument Corp.,

*Corresponding author. Tel: +81-80-5413-5624, E-mail : nanosearcher77(a)gmail.com
2012) method the measurement with based on constanttemperature scanning probe microscopy (SPM), from a material science standpoint, the linear expansion coefficient and transition temperature (i.e., the temperature at which the linear expansion coefficient becomes zero) of microbial cells as they are heated (Nakanishi et al., 2013; 2015).

Although there are standard methods for measuring thermal conductivity (such as ISO 22007-2(2008)), these methods are designed for thin-layer samples; as such, we were unable to use them to measure the thermal conductivity of microbial cells. In this study, to develop the measurement method of the thermal conductivity per one cell newly, for this reason, we used a nanoTA constant-temperature scanning thermal microscopy (SThM) system (Gotzen et al., 2005). This instrumentation was used to evaluate the linear expansion coefficient and transition temperature of individual microbial cells. We developed a method to evaluate thermal conductivity by measuring the degree to which 
a thermal probe receiving constant thermal energy cools when it contacts a cell. This method allows us to measure the thermal conductivity of individual microbial cells, which until now was not possible.

Spores were prepared from spore-forming Geobacillus stearothermophilus NBRC 13737, Bacillus coagulans DSM 1, B. subtilis ver. subtilis NBRC 13719T, B. megaterium NBRC 15308T, B. licheniformis NBRC 12200, Thermoanaerobacter mathranii DSM 11426, and Moorella thermoacetica DSM521T. In addition to the Bacillus lineages listed above, vegetative cells were prepared for three bacterial strains (Staphylococcus aureus NBRC 100910, Escherichia coli IFO 3301, and Pseudomonas aeruginosa ATCC 10145) and one yeast strain (Saccharomyces pastorianus RIB 2010) (Nakanishi et al., 2013)

Bacteria were cultured in nutrient broth (Difco, Becton Dickinson and Co., Franklin Lakes, NJ, USA); Geobacillus stearothermophilus was cultured at $60^{\circ} \mathrm{C}$; all other bacteria were cultured at $35^{\circ} \mathrm{C}$. Vegetative cells were used in the log phase $\left(\mathrm{OD}_{600}\right.$ 0.8-1.0) after 4 to $12 \mathrm{~h}$ of culture. For experiments in which spores were used, the bacteria were cultured under the same conditions for 96 h (Nakanishi et al., 2013). For T. mathranii and $M$. thermoacetica spores, the bacteria were cultured in modified TGC culture medium (Nissui Pharmaceutical Co. Ltd., Tokyo, Japan) at $60^{\circ} \mathrm{C}$ for $72 \mathrm{~h}$. The yeast $S$. pastorianus was cultured in YM Broth (Difco) at $25^{\circ} \mathrm{C}$ for $48 \mathrm{~h}$. Spores were collected from the culture fluid as reported previously (Nakanishi et al., 2013).

To determine the precision of the thermal conductivity measurements obtained using the newly developed method, we prepared microbeads ( 1 to $3 \mu \mathrm{m}$ in diameter) made of three types of plastics with known thermal conductivity properties (i.e., polyethylene $[\mathrm{PE}]$, polypropylene $[\mathrm{PP}]$, and polyethylene terephthalate $[\mathrm{PET}]$ ). Those were of a size similar to microbial cells (Atect Co. Ltd., Osaka, Japan).

With regard to metal materials, although methods exist for measuring metal microspheres, due to difficulties in preparing metal microbeads, we used data reported in the literature to estimate the thermal conductivity of metal microspheres.

To determine the volume, linear expansion coefficient, and transition temperature of cell samples, we utilized a nanoTA-SPM system (Gotzen et al., 2005) consisting of a nanoTA (Anasys Instrument Corp., Santa Barbara, USA) combined with a nano search SPM microscope (SFT-3500, Shimadzu, Kyoto, Japan). In addition, we measured the thermal conductivity of microbial cells using the nanoTA-SThM system. For thermal measurements, we used an AN-1 probe (Nippon Thermal Consulting, Tokyo, Japan) with a spring constant of 0.2 $\mathrm{N} / \mathrm{m}$.

Assuming that the microbial cells were uniform substances and taking into consideration the fact that, according to the Dulong-Petit law, thermal conductivity decreases with increasing quantity of heat applied (in this case, with increasing probe temperature), we set the probe temperature near the transition temperature at which the linear expansion coefficient of microbial cell becomes zero (Nakanishi et al., 2013). The probe was heated to to a constant $80^{\circ} \mathrm{C}$ (176K) for all samples. The cantilever, which comprises a thin layer of silicon, is maintained at constant temperature by applying a constant stress and voltage (e.g., application of $1 \mathrm{~V}$ provides heating to $80^{\circ} \mathrm{C}$ ) and used to scan the sample surface.

Thermal conductivity is calculated based on the decline in temperature of the cantilever (when it is in contact with the sample) and the sample volume. The decline in temperature associated with the sample is compared to that associated with a reference material (e.g., glass, epoxy resin, or gold) to calculate the thermal conductivity of the sample. The magnitude of the temperature change is automatically calculated from the voltage applied, as follows. A drop in temperature is sensed by the probe tip, and the degree of change in the temperature is automatically calculated from the voltage that must be applied for a return to the initial

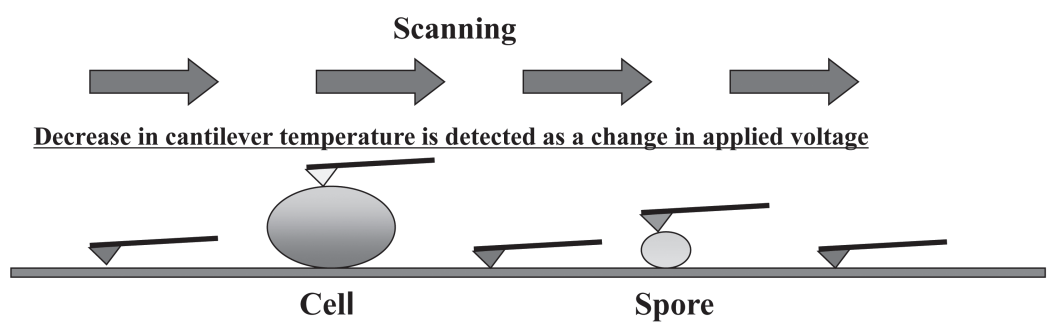

FIG. 1. Principle underlying thermal conductivity measurement using SThM. A cantilever maintained at a constant temperature and under constant stress is used in tapping mode to scan a certain area containing the sample and generate an image of the temperature variation within the scanned area. The maximum area that can be scanned is $100 \times 100 \mu \mathrm{m}$. 
temperature.

Measurements were carried out in tapping mode. The scan rate was set to cover a $10 \times 10 \mu \mathrm{m}$ area in $10 \mathrm{~min}$. The temperature at the tip of the thermal probe was controlled by adjusting the voltage, which was then used to calculate the heat quantity. The surface temperature of the sample was calculated from the temperature drop of the thermal probe. Loss of heat to the atmosphere was ignored, as calibration was performed at ambient temperature prior to measurement (Anasys Instruments, 2012).

Because the $T_{v}$ level measures glass (as control) and a cell at the constant same heat probe temperature set for measurement, for the thermal conductivity of the cells, by the comparison with the thermal conductivity of the glass, can be calculated as:

$\lambda_{s}=1.05\left(T_{v}-T_{\text {glass }}\right) /\left(T_{v}-T_{s}\right) \cdots(1)$

$\lambda_{s}$ : thermal conductivity $(\mathrm{W} / \mathrm{m} \cdot \mathrm{K})$

1.05: thermal conductivity of the glass $(\mathrm{W} / \mathrm{m} \cdot \mathrm{K})$

$\mathrm{T}_{\mathrm{v}}$ : thermal probe temperature $\left(80^{\circ} \mathrm{C}(176 \mathrm{~K})\right)$

$\mathrm{T}_{\text {glass }}$ : temperature when thermal probe touched of the glass surface $(\mathrm{K})$.

$\mathrm{T}_{\mathrm{s}}$ : sample surface temperature when thermal probe touched of the glass surface $(K)$ The thermal conductivity of the glass used as the substrate was $1.05 \mathrm{~W} / \mathrm{m} \cdot \mathrm{K}$. The principle underlying the measurement method is illustrated in Fig. 1.
Using a cantilever with the SThM system, we scanned the cell surface at a constant temperature of $80^{\circ} \mathrm{C}$ (176K) (by application of $1 \mathrm{~V}$ ) and constant stress in tapping mode to measure the thermal conductivity of individual cells (Fig.1). We calculated the thermal conductivity from the decrease in cantilever temperature (compared to that of the reference material) and the cell volume.

The thermal conductivity of various types of plastic microbeads was measured using the nanoTA-SThM method, was found to be fairly consistent with those reported in the literature (David, 2003; Shimadzu Corp., 2012) (Table 1). Images of a bacterial vegetative cell and spore obtained using a heated thermal probe are presented in Fig.2.

For each surface temperature scan, we calculated

TABLE 1. Known and measured (SThM) thermal conductivities of plastic materials.

\begin{tabular}{lccc}
\hline Plastic & $\begin{array}{c}\text { Measured value } \\
(\mathrm{SThM}) \\
(\mathrm{W} / \mathrm{m} \cdot \mathrm{K})\end{array}$ & $\begin{array}{c}\text { Thermal } \\
\text { conductivity } \\
(\mathrm{W} / \mathrm{m} \cdot \mathrm{K})\end{array}$ & $\begin{array}{c}\text { Melting point } \\
\left({ }^{\circ} \mathrm{C}\right)\end{array}$ \\
\hline PE & $0.48 \pm 0.04$ & 0.46 & 116 \\
PP & $0.14 \pm 0.02$ & 0.12 & 168 \\
PET & $0.11 \pm 0.04$ & 0.14 & 235 \\
\hline
\end{tabular}
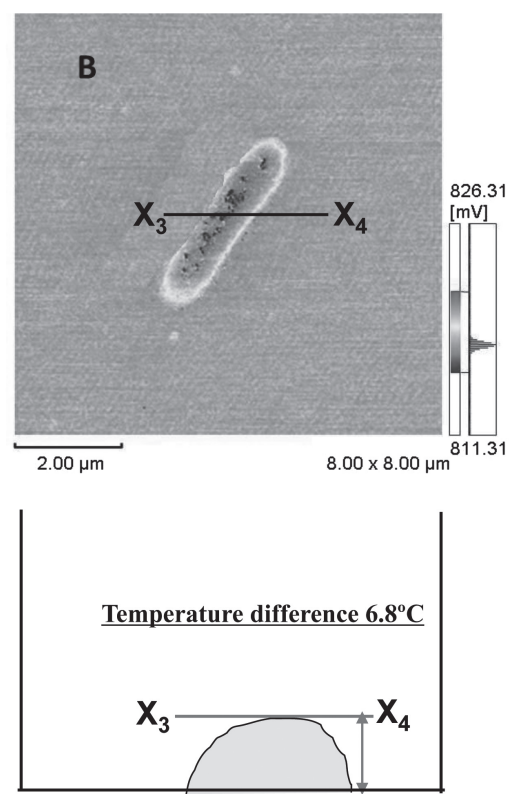

FIG. 2. SThM image (surface temperature scan) of B. coagulans cells.

(A) B. coagulans spore. (B) B. coagulans vegetative cell. In both thermographs, the $\mathrm{mV}$ value $(8.0 \times 8.0 \mu \mathrm{m})$ represents the voltage applied to maintain the thermal probe at the set temperature (the temperature of the surface sample is calculated relative to the voltage drop associated with scanning a glass surface, so the temperature in this figure shows a difference of sample surface temperature and the temperature of the glass.). 
TABLE 2. Thermal conductivities of microbial vegetative cells and spores and selected materials $(\mathrm{W} / \mathrm{m} \cdot \mathrm{K})$.

\begin{tabular}{|c|c|c|c|}
\hline $\begin{array}{l}\text { Thermal conductivity } \\
(\mathrm{SThM})(\mathrm{W} / \mathrm{m} \cdot \mathrm{K})\end{array}$ & $\begin{array}{l}\text { height along the } z \text {-axis } \\
\qquad\left(\times 10^{-6} \mathrm{~m}\right)\end{array}$ & $\begin{array}{c}\text { Transition } \\
\text { temperature }(\mathrm{K}) *\end{array}$ & $\begin{array}{c}\mathrm{C}=\text { thermal transfer } \\
\text { needed to kill a single } \\
\text { microbial cell }(\mathrm{W})\end{array}$ \\
\hline
\end{tabular}

\begin{tabular}{lllll}
\hline Spores & & & \\
G. stearothermophilus & $0.33 \pm 0.021$ & $5.92 \pm 0.72$ & $342 \pm 1.7$ & $5.18 \times 10^{-16}$ \\
B. coagulans & $0.41 \pm 0.018$ & $8.58 \pm 1.33$ & $268 \pm 3.4$ & $6.72 \times 10^{-16}$ \\
B. subtilis ver. subtilis & $0.37 \pm 0.015$ & $3.37 \pm 0.02$ & $257 \pm 4.5$ & $2.24 \times 10^{-16}$ \\
B. megaterium & $0.43 \pm 0.023$ & $3.64 \pm 1.80$ & $235 \pm 1.1$ & $2.47 \times 10^{-16}$ \\
B. licheniformis & $0.45 \pm 0.011$ & $4.55 \pm 1.09$ & $225 \pm 1.6$ & $3.03 \times 10^{-16}$ \\
T. mathranii & $0.30 \pm 0.009$ & $5.21 \pm 1.55$ & $462 \pm 1.1$ & $6.02 \times 10^{-16}$ \\
M. thermoacetica & $0.29 \pm 0.011$ & $4.76 \pm 1.94$ & $552 \pm 1.4$ & $6.56 \times 10^{-16}$ \\
Vegetable cells & & & & \\
G. stearothermophilus & $0.69 \pm 0.023$ & $71.2 \pm 6.35$ & $255 \pm 3.5$ & $8.75 \times 10^{-15}$ \\
B. coagulans & $0.70 \pm 0.015$ & $82.6 \pm 9.82$ & $195 \pm 2.5$ & $6.82 \times 10^{-15}$ \\
B. subtilis ver. subtilis & $0.74 \pm 0.022$ & $70.2 \pm 7.23$ & $160 \pm 2.4$ & $4.31 \times 10^{-15}$ \\
B. megaterium & $0,75 \pm 0.016$ & $65.7 \pm 6.16$ & $148 \pm 2.7$ & $3.50 \times 10^{-15}$ \\
B. licheniformis & $0.72 \pm 0.012$ & $77.6 \pm 4.09$ & $135 \pm 7.3$ & $3,24 \times 10^{-15}$ \\
S. aureus & $0.66 \pm 0.007$ & $23.4 \pm 0.35$ & $136 \pm 1.7$ & $9.11 \times 10^{-16}$ \\
E. coli & $0.74 \pm 0.032$ & $62.2 \pm 8.72$ & $118 \pm 1.3$ & $1.89 \times 10^{-15}$ \\
P. aeruginosa & $0.69 \pm 0.026$ & $75.1 \pm 6.30$ & $133 \pm 1.4$ & $2.90 \times 10^{-15}$ \\
S. pastorianus & $0.61 \pm 0.024$ & $228 \pm 16.2$ & $129 \pm 2.4$ & $7.23 \times 10^{-15}$ \\
\hline *Nakanishi et al., 2013 & & & & $\mathrm{n}=10$
\end{tabular}

the difference in temperature between the sample surface and the glass stage, which we then used to calculate the thermal conductivy (Table 2). We were able to measure the transition temperature and thermal conductivity (thermal resistance) of individual microbial cells using the nanoTA-SPM and nanoTA-SThM systems, respectively. We also observed that the thermal conductivity of vegetative cells $(0.61$ to $0.75 \mathrm{~W} / \mathrm{m} \cdot \mathrm{K})$ was greater than that of spores $(0.29$ to $0.45 \mathrm{~W} / \mathrm{m} \cdot \mathrm{K})$ of the same microbial species. Differences in thermal conductivity between species were found to be small. The above results provide underlying support for the observation that spores are more thermally resistant than vegetative cells from the standpoint of thermal conductivity. It is thought that the difference between vegetable cell and spore water content depends on the difference in this thermal conductivity (Parcedes-Sabja et al., 2008). We want to continue examining the influence of water content as a future research theme.

It is possible to calculate the thermal energy required for heat sterilization of microbial cells as physical units, based on the thermal energy applied to the nanoTASPM thermal probe and the thermal conductivity data obtained using the SThM system. Specifically, we will be able to calculate the thermal energy needed to kill

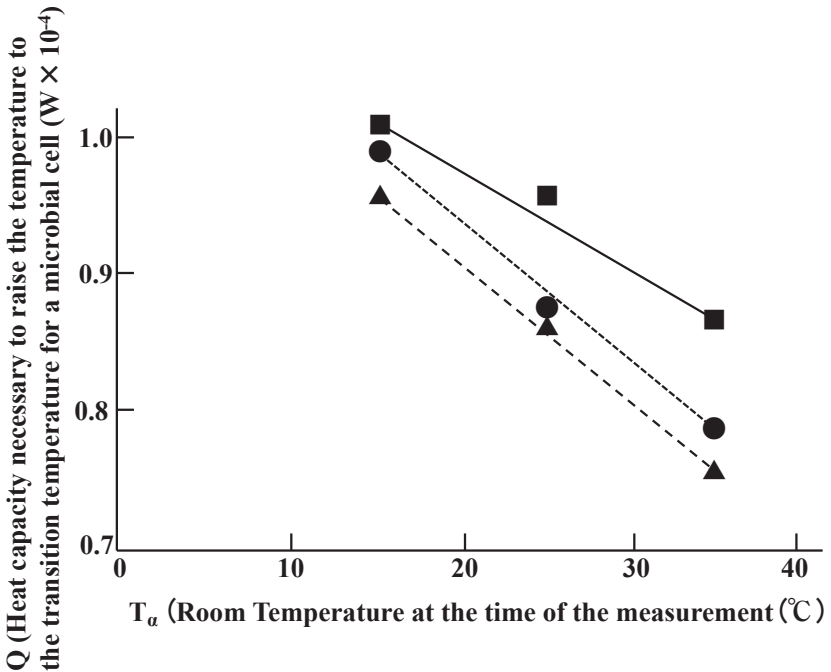

FIG. 3. The correlation between $Q$ (heat capacity necessary to raise the temperature to the transition temperature for a cell $(W)$ ) and the room temperature at the time of the measurement

Closed squares, B. subtilis; closed circles, B. megaterium; closed triangles, $B$. licheniformis 
(A)

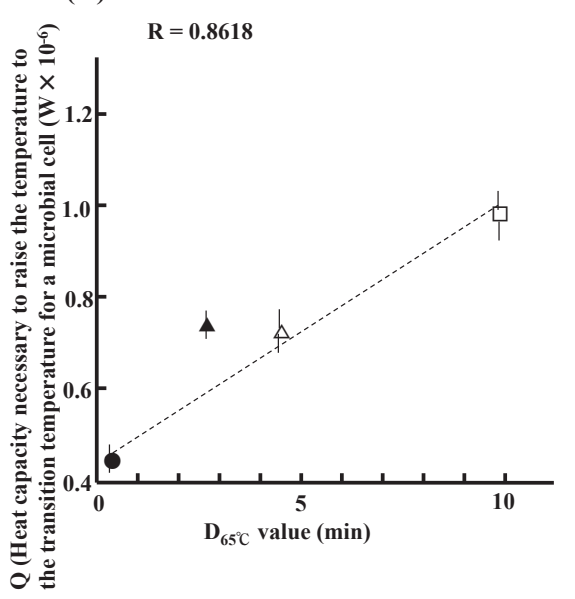

(B)

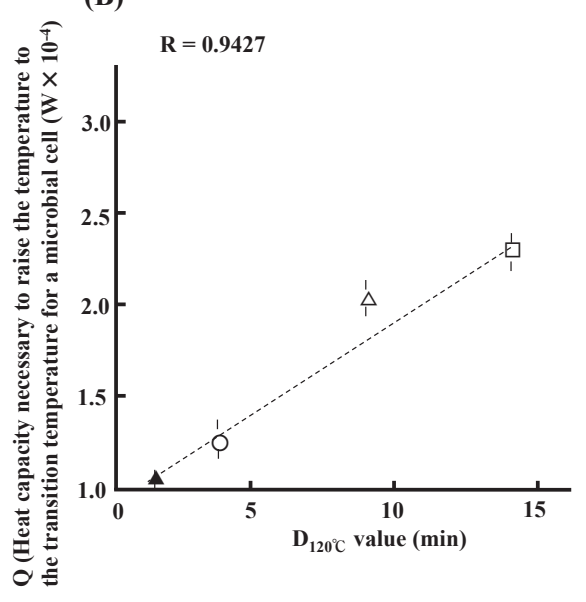

(C)

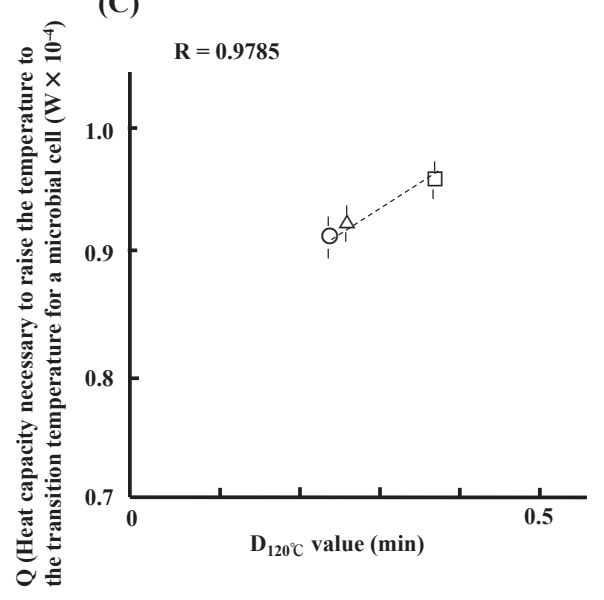

FIG. 4. Correlation between $Q$ (heat capacity necessary to raise temperature to transition temperature a cell $(W)$ ) and $D$ value (A) Correlation between $Q$ (heat capacity necessary to raise temperature to transition temperature a cell (W)) and $D_{65^{\circ} \circ}$ for vegetative cells of four bacterial strains.

Open square, B. subtilis; open triangle, S. aureus; closed triangle, P. aeruginosa; closed circle, E. coli.

(B) Correlation between $Q$ (heat capacity necessary to raise the temperature to the transition temperature for a cell $(\mathrm{W})$ ) and $D_{120^{\circ} \mathrm{c}}$ for spores of four bacterial strains with high heat resistance.

Open square, M. thermoacetica; open triangle, T. mathranii; open circle, G. stearothermophillus; closed triangle, B. coagulans.

(C) Correlation between $Q$ (heat capacity necessary to raise temperature to transition temperature a cell $(W)$ ) and $D_{120^{\circ} \circ}$ for spores of four bacterial strains with low heat resistance.

Open square, B. subtilis; open circle, B. megaterium; open triangle, B. licheniformis

individual cells based on the actual thermal energy applied to the probe up to the transition temperature $\left(T_{g}\right)$ of the linear expansion coefficient (which is believed to be the "kill temperature" for cells) and the thermal conductivity values obtained using the method developed in this study.

$\mathrm{Q}=\lambda_{s} \cdot h\left(T_{g}-t_{a}\right) \cdots(2)$

Q: Heat capacity necessary to raise temperature to transition temperature of a microbial cell $(\mathrm{W})$

$\lambda_{s}$ : microbial cell thermal conductivity $(\mathrm{W} / \mathrm{m} \cdot \mathrm{K})$

$h$ : cell or spore height along the $z$-axis $\left(\times 10^{-6} \mathrm{~m}\right)$

$T_{g}$ : transition temperature $(\mathrm{K})$

$t_{a}$ : temperature before heating $(\mathrm{K})$ (room temperature, $\left.25^{\circ} \mathrm{C}(77 \mathrm{~K})\right)$

Transition temperature $T_{g}$ had a strong relationship with the killing temperature of microbial cells as having thickened one in a former report sentence (Nakanishi et al., 2015). It were shown the extinction heat capacity level that tried a calculation by expression (2) in Table 2. After taking three phases of $15^{\circ} \mathrm{C}(59 \mathrm{~K}), 25^{\circ} \mathrm{C}(77 \mathrm{~K})$, and $35^{\circ} \mathrm{C}(95 \mathrm{~K})$, at room temperature to measure, room temperature was proportional to $Q$ (Fig.3). Differences between the transition temperature and room temperature show that As a result of having compared it about vegetable cells and spores, the difference of temperature with the transition temperature became small so that room temperature was high, and $Q$ became small, too. correlation was accepted between $Q$ and the $D$ levels (Fig.4). We think that further investigation regarding water content is necessary to empirically verify this hypothesis (Parcedes-Sabja et al., 2008) with the heat resistance expressed with a heat properties of matter level of a transition temperature, the thermal conductivity individual these individual homicide extinction energy more including water content.

\section{ACKNOWLEDGMENT}

We would like to express our appreciation Shimadzu Corp. for their invaluable advice.

\section{REFERENCES}

Anasys Instrument Corp. (2012) Anasys Instruments: nanoTA Technology Santa Barbara, California USA, http://www. anasysinstruments.com/nanaTA. php? fi=technology. Accessed 10 Oct 2013.

David R. Lide (ed) (2003) CRC Handbook of Chemistry and Physics, 84th Edition. CRC Press. Boca Raton, Florida; Section 12, Properties of Solids: Thermal and Physical Properties of Pure Metals/Thermal Conductivity of Crystalline Dielectrics/Thermal Conductivity of Metals and Semiconductors as a Function of Temperature.

Gotzen, N-A. and Assche, G. V. (2005) nano-TATM nano thermal analysis, Application Note \#3, Anasys Instrument Corp., Santa Barbara, CA, USA.

Nakanishi, K., Kogure, A., Deuchi, K., Kuwana, R., Takamatsu, H., and Ito, K. (2013) With respect to coeffi- 
180 K. NAKANISHI ET AL.

cient of linear thermal expansion, bacterial vegetative cells and spores resemble plastics and metals, respectively. J. Nanobiotechnol., 11: 33.

Nakanishi, K., Kogure, A., Deuchi, K., Kuwana, R., Takamatsu, H., and Ito, K. (2015) The heat resistance of microbial cells represented by $d$ values can be estimated by the transition temperature and the coefficient of linear expansion. Bicontrol. Sci., 20, 291-294.

Parcedes-Sabja, D., Setlow, B., Setlow, P., and Sarker, R.
(2008) Characttrerization of Clostridium perfringens spores that lack spoVA proteins and dipicolinic acid. J. Bacteriol., 190, 4648-4659.

Plastics (2008) Determination of thermal conductivity and thermal diffusivity - Part 2: Transient plane heat source (hot disc) method (ISO/TC 61/SC 5) ISO 22007-2.

Shimadzu Corp. (2012) Scanning Probe Microscopy (SPM) SPM+nanoTA2., Kyoto Japan, http://www.shamdzu.com/ an/surface/nano-ta.html. Accessed 10 Oct 2013. 